\title{
Typhoon Eye Effect Vs. Ripple Effect: the Role of Family Size on the Mental Health Under the COVID- 19 Pandemic in Pakistan
}

\section{Stephen X Zhang ( $\sim$ stephen.X.zhang@gmail.com )}

Associate Professor, University of Adelaide, Australia; Address: 9-28 Nexus10 Tower, 10 Pulteney St, Adelaide SA 5000, Australia https://orcid.org/0000-0001-6123-1193

\section{Tooba Lateef}

University of Karachi

Jiyao Chen

Oregon State University

\section{Muhammad Tahir}

Sir Syed University of Engineering and Technology

\section{Teba Abdul Lateef}

University of Karachi

\section{Bryan Chen}

Crescent Valley High School

Jizhen Li

Tsinghua University

\section{Research}

Keywords: COVID-19, Pakistan, Typhoon eye effect, Ripple effect, Family size, Mental health

Posted Date: January 5th, 2021

DOI: https://doi.org/10.21203/rs.3.rs-139095/v1

License: (c) (1) This work is licensed under a Creative Commons Attribution 4.0 International License. Read Full License

Version of Record: A version of this preprint was published at Globalization and Health on March 29th, 2021. See the published version at https://doi.org/10.1186/s12992-021-00685-5. 


\section{Abstract}

Background: The recent outbreak of COVID-19 impacts the mental health of people worldwide. The mental conditions and the associated predictors of adults in Pakistan, the fifth most populous country in the world, during the COVID-19 remains understudied. We aim to investigate distress, anxiety, and overall mental health and their associated predictors among Pakistani adults in this pandemic. We specifically examine the mental health issues based on the distance to the epicenter, a predictor that has revealed opposing evidence in other countries based on the theories of typhoon eye effect and ripple effect. The samples consist of 601 adults who were surveyed online about 2.5 months into the outbreak across Pakistan with varying distance to the epicenter of COVID-19 of Karachi in Pakistan.

Results: The results showed that $9.2 \%$ and $19.0 \%$ of the participants surpassed the cut-off of distress and anxiety disorders, respectively. Overall, the distance to the epicenter positively predicted the mental health of adults in Pakistan, and family size negatively moderated this effect. The distance to the epicenter negatively predicted distress and anxiety disorders for adults in large families, which are quite common in Pakistan.

Conclusion: The evidence of the study interestingly finds the prediction of the mental health of people by their distance to the epicenter depends on the family. The evidence of this study can help to provide the initial indicator for mental health care providers to screen vulnerable groups in Pakistan, a populous country that continues struggling to cope with the COVID-19 pandemic.

\section{Introduction}

In Pakistan, the first case of COVID-19 appeared on February 26, 2020 in Karachi, the largest city and the financial, industrial, and trading hub of the country. The initial cases were imported to Karachi from abroad but later, community spread started, and Karachi became the initial epicenter of the virus infection in Pakistan [1]. As COVID-19 spreads, panic among the public happened across the country, as it has happened in other countries such as Iran, Italy, Peru, and Bolivia [2-5]. For instance, one study of students has shown moderate anxiety and distress as pandemic affects daily life activities in Pakistan [6].

While it seems that people closer to the center of any disastrous event would be affected more and in turn have more mental issues. The effect of a catastrophic event declines for people with greater geographical distances to the epicenter, known as the "ripple effect" [7]. However, some findings have demonstrated an opposite effect referred to as "typhoon eye effect". In the 2008 Wenchuan earthquake, it was first observed that people closer to the area of crisis felt calmer [8]. Later, the same phenomenon was observed during different public health emergencies [9-11].

In the ongoing COVID-19 pandemic, the opposite theories of typhoon eye effect and ripple effect have been reported. Some studies supported the ripple effect [12, 13], yet some others supported the typhoon eye effect [14-16]. Hence, these inconsistent findings limited the explanation of both theories. Up till now, 
there has been no research conducted in the general population of Pakistan to assess anxiety and distress.

Therefore, the present study aims to study the mental disorders in Pakistan under COVID-19 pandemic based on the two opposite theories of typhoon eye effect and ripple effect. Moreover, this study is the first to examine the prediction of the typhoon eye effect and ripple effect on people living with varying sizes of family, given people tend to live with larger families in countries such as Pakistan, and the larger family may either drain or provide buffering resources to mental issues. This study will also be one of the first medical papers to the study of mental health among adults in varying geographical locations in Pakistan. The findings of the research can help to pinpoint useful predictors that will help to provide targeted mental health support in vulnerable groups during the COVID-19 pandemic that still goes on in Pakistan, the fifth most populous country in the world.

\section{Methods}

\section{Study Context}

The first case of COVID-19 in Pakistan was reported on February 26, 2020 in Karachi [17]. The largest city of Pakistan and the capital of Sindh, with a population of 16 million [18] has the high burden of disease as compared to other cities [1]. At the time of the study, Feb 26 to May 11, 2020, there were 9480 cases in Karachi, representing $41.5 \%$ of the 22,820 total active cases in the entire country [17]. Hence Karachi was a clear epicenter in Pakistan at the time of the study.

\section{Data collection and sample}

About 2.5 months into the outbreak, on May $4^{\text {th }}-11^{\text {th }} 2020$, we conducted an online survey of adults from all over Pakistan. On May $4^{\text {th }}, 2020$, when the survey started, the total number of confirmed cases of COVID-19 reached 21,501, and the death toll reached 486 in Pakistan [17].

The study was approved by the Institutional Bioethical Committee of the University of Karachi (IBC KU -143/2020). The participants, after their consent, filled the online survey voluntarily. The survey promised the participants the confidentiality and anonymity of their responses. The participants could answer the survey in Urdu (the back-translated version) or English (the version developed originally).

\section{Variables}

The participants reported their demographic characteristics such as age, gender, education, and marital status. They also reported their family size and daily exercise hours in the past week. We computed the distance from their geographical locations to Karachi, the COVID-19 epicenter of Pakistan.

The outcome variables included distress, anxiety, and, mental health. Distress was measured by $\mathrm{K} 6$, the six-item Kessler mental distress scale $(0=$ never, $4=$ almost all of the time; $a=0.83)$ with the cut-off point of $13[19,20]$. Anxiety was measured by the seven-item Generalized Anxiety Disorder-7 scale (GAD-7) $(0=$ 
never, rarely, 3 = always; $a=0.88$ ) with the cut-off point of 10 [20-22]. Mental health was assessed by 12 item Short Form-12 (SF-12) [22-24]. SF12 cover eight sub-scales including physical functioning, physical role, body pain, general health, functionality, social functioning, emotional role, and mental health $(a=$ $0.74)$.

\section{Data analysis approach}

We used Stata 16.0 to summarize the variables and predict distress and anxiety by logistic regression and mental health by ordinary least squares regression with a $95 \%$ confidence level.

\section{Results}

\section{Descriptive findings}

The results showed that $47.6 \%$ of the 601 working adults were female, $62.4 \%$ were younger than 29 years old, $26.0 \%$ were between 30 to 39 years, and $11.6 \%$ were 40 years or older. $67.7 \%$ of the participants were single, $30.8 \%$ married, and $1.5 \%$ divorced. Most of the participants (70.5) had an undergraduate degree or higher with few participants (29.0) having a high school diploma (intermediate). On average, they exercised 0.77 hours each day with an SD of 0.79 hours. Overall, they had a family size of 6.03 with SD of 3.10 and resided 0.27 thousand kilometers away from Karachi, Sindh with SD of 0.51 thousand kilometers (Table 1).

\section{Descriptive and comparative findings on the outcome variables}

About one-tenth of participants surpassed the cut-off of distress (9.2\%) and about one-fifth of participants surpassed that of anxiety (19.0\%). By comparing our findings with those in 11 studies using similar measurements, we found that overall the mental health conditions of Pakistani adults were comparable or less than those in several samples in China, Spain, and Italy with one exception (Table 2 for a summary). Anxiety disorder in our sample was higher than that in a sample of adults in China in late Feb 2020 [25].

\section{Predictors of distress, anxiety, and mental health}

The distance to the epicenter of COVID-19 in Pakistan negatively predicted the mental health of adults, but the relationship depended on their family size $(b=-0.71 ; 95 \% \mathrm{Cl}:-1.04$ to $-0.38 ; P=0.000)$. Margin analysis showed that the distance to the epicenter positively predicted mental health for adults in small families (e.g. at a single-member family: $b=2.79 ; 95 \% \mathrm{Cl}: 0.28$ to $5.30 ; \mathrm{P}=0.039$ ). In contrast, the distance to the epicenter negatively predicted mental health for adults in large families (e.g. at an 8-member family: $b=-2.19 ; 95 \% \mathrm{Cl}:-3.85$ to $-0.54 ; \mathrm{P}=0.009)$. Similarly, the relationship of the distance to the epicenter and mental health disorders of adults also depended on their family size (OR=1.25; $95 \% \mathrm{Cl}$ : 1.04 to 1.49 ; $\mathrm{P}=0.017$ for distress, and $\mathrm{OR}=1.14 ; 95 \% \mathrm{Cl}: 1.03$ to $1.26 ; \mathrm{P}=0.015$ for anxiety). Margin analysis showed 
that the distance to the epicenter positively predicted distress disorder for adults in large families (e.g. at an 8-member family: $\mathrm{OR}=0.065 ; 95 \% \mathrm{Cl}: 0.032$ to $0.098 ; \mathrm{P}=0.000$ ) and anxiety disorder (e.g. at an 8member family: $\mathrm{OR}=0.066 ; 95 \% \mathrm{Cl}: 0.008$ to $0.12 ; \mathrm{P}=0.026$ ) (Figure 1 ).

In addition, adults who exercised more have better mental health ( $b=1.28 ; 95 \% \mathrm{Cl}: 0.31$ to $2.25 ; \mathrm{P}=0.010)$ and less likely to experience distress disorders $(\mathrm{OR}=0.66 ; 95 \% \mathrm{Cl}: 0.45$ to $0.96 ; \mathrm{P}=0.028)$. The results also suggest that the older the person, the better the mental health $(b=0.28 ; 95 \% \mathrm{Cl}: 0.06$ to $0.40 ; \mathrm{P}=0.007)$.

\section{Discussion}

Pandemics have a myriad impact on the mental health of people. In the recent outbreak of COVID-19, it has been reported that COVID-19 itself with many other factors has increased mental issues in various countries $[5,24,26-28]$. To the best of our knowledge, this is the first study to examine the typhoon eye effect or ripple effect from the epicenter among Pakistani adults. The findings of mental distress and anxiety scales revealed the prevalence of moderate distress and anxiety in our sample. Compared to other recently published studies, the results showed that the rate of anxiety and distress among Pakistani adults was greater as compared to those in China [25], whereas lower as compared to Italy, Spain, and United States $[3,29,30]$. These differences might be due to a smaller number of reported cases and deaths compared to the countries that have high distress and anxiety. With regard to the variables associated with distress, anxiety, and mental health in Pakistan, family size and exercise were worth noting predictors found in our sample. Previous literature revealed that geographical distance from the epicenter as an important prognosticator during catastrophic events [15]. In the present study, the findings overall showed that participants residing distantly from the epicenter have better mental health with less distress and anxiety, supporting the ripple effect rather than the typhoon eye effect $[4,31]$. However, the association can diverge based on individuals' family size. The mental disorder decreased by the distance to the epicenter for individuals in small families, indicating the typhoon eye effect. By contrast, mental disorders increased by the distance to the epicenter for individuals in larger families, showing the ripple effect.

Our results on the ripple effect vs. typhoon eye effect, together with other studies on the same topic in Peru, Brazil and China $[4,16,31]$, suggest the prediction of these two opposing theories may differ based on the countries studied. Such differences are understandable, as countries vary in their geography, media and social media reporting, medical systems, cultures, the availability of personal protective equipment (PPE), labor and employment conditions, the policies of lockdown, the ease of working from home, maintaining a living in a pandemic, and the information in both mainstream and social media, etc. [2]. The results therefore suggest we need to identify the predictive effect of the ripple effect vs. typhoon eye effect as a predictive model of mental health in individual countries during the COVID-19 pandemic. Our results suggest such studies can focus on identifying relevant contingency factors in individual countries. In Pakistan, we focused on family size, and the possible explanation for family size to reverse the effect of the ripple effect vs. typhoon eye effect might be due to socio-economic burden on the families due to lockdown in the country. As studies have shown that financial constraints or economic 
hardships not only increased behavioral problems but also damaged the physical and mental health status of individuals and their families [32]. Thus, our findings identify family size as a critical contingency factor in the prediction of typhoon eye effect and ripple effect. Future research can focus on identifying unique contingency factors in the country of the study.

As in previous studies in Iran, Brazil and China [2, 16, 24], our sample also identified exercise hours as one of the predictors of distress, anxiety, and mental health during COVID-19. The results showed that participants who put in more hours for physical activity in terms of daily exercise in their routine had better mental health and were less likely to develop distress and anxiety symptoms. Many studies have reported that performing daily exercise might have an impact on anxiety and distress symptoms [33]. Due to the sedentary lifestyles in COVID-19 pandemic, it has been observed that people gave less attention to their physical health than in normal circumstances [34]. Thus, particularly in this pandemic era when people were extra stressed, adding physical activity in the daily routine can play a role in reducing distress and anxiety. In comparison with the recent studies of Iran, China, and Brazil [35-37], age also predicted mental health in the Pakistani population. The results showed that older people had better mental health, which might be due to the joint family system in Pakistan. It has been reported that traditional family systems, such as those in South Asia, can contribute to healthier mental states among older people as compared to those living in smaller nuclear family systems [38]. The positive attitude from a lack of information about COVID-19 could also be another factor for better mental health of older people [39]. As compared to older people, younger people rely more on social media and the internet that have helped to spread negative information on the pandemic $[14,25]$.

The overall findings of the present study can help to identify the vulnerable individuals in Pakistan during this crisis of COVID-19. Exercise, family size, age, and distance to the epicenter are the key predictors of distress, anxiety, and mental health in Pakistan during this pandemic. More specifically the relationship of the geographical distance to the epicenter with distress, anxiety, and mental health represented the ripple effect in large families. However, the relationship varied depending on family size and showed the typhoon eye effect in small families. Thus, the results suggest that the geographical distance to epicenter, with an important contingency of facility size, can play a major role in screening of people with high risk.

This study had some limitations. During the survey dates, the total amount of active cases of COVID-19 in Pakistan had yet to reach its peak, and the situation continues to evolve. In addition, as the study was conducted through an online questionnaire, selective participation and coverage area error might be present. While we aimed for broad coverage of the adults in various parts of Pakistan, we do not claim our sample to be representative of the adults' population in Pakistan.

\section{Conclusion}

In conclusion, the present study uncovered the prevalence of distress and anxiety disorders in Pakistani adults during COVID-19. The results indicate that geographical distance is a crucial factor in screening vulnerable groups and suggest future studies to examine the use of the typhoon eye effect or ripple effect 
in terms of identifying mentally vulnerable people with a focus to identify the relevant contingency factors.

\section{Declarations}

\section{Ethics Approval and Consent to Participate}

The study was approved by Institutional Bioethical Committee, University of Karachi (approval no. IBC KU-143/2020). Each study participant filled the online questionnaire voluntarily after their consent.

\section{Consent for Publication}

Not applicable

\section{Availability of Data and Materials}

The datasets presented in this article are not available. Requests to access the datasets should be directed to the corresponding author.

\section{Competing Interest}

The authors declare that there are no potential conflicts of interest with respect to the research, authorship, and/or publication of this article.

\section{Funding}

This paper is supported by the MOE Project of Key Research Institute of Humanities and Social Sciences at Universities (16JJD630005)

\section{Authors Contribution}

T. L.: Investigation (data collection), Writing - Original, Writing - Review \& Editing

J. C.: Investigation, Formal analysis, Investigation, Writing - Original, Writing - Review \& Editing, Validation

M. T.: Investigation (data collection), Resources, Writing - Review \& Editing

T. A. L.: Investigation (data collection), Writing - Review \& Editing

B. C.: Visualization; Writing - Review \& Editing

J. L.: Resources

S. X. Z.: Conceptualization, Investigation, Methodology, Formal analysis, Writing - Original, Writing Review \& Editing, Supervision 
All authors have read and approved the final manuscript.

\section{Acknowledgements}

We thank the Institutional Bioethical Committee, the University of Karachi and the MOE Project of Key Research Institute of Humanities and Social Sciences at Universities (16JJD630005) for their support. We also thank all individuals who have devoted their time to participate in this study.

\section{References}

1. Ilyas N, Azuine RE, Tamiz A. COVID-19 pandemic in Pakistan. Int J Transl Med Res Public Health. 2020;4(1):37-49. doi: 10.21106/ijtmrph.139.

2. Jahanshahi AA, Dinani MM, Li J, Zhang SX. The distress of Iranian adults during the Covid-19 pandemic - More distressed than the Chinese and with different predictors. Brain, Behav Immun. 2020;87(2020):124-125. doi: 10.1016/j.bbi.2020.04.081.

3. Moccia L, Janiri D, Pepe M, Dattoli L, Molinaro M, Martin VD, et al. Affective temperament, attachment style, and the psychological impact of the COVID-19 outbreak: an early report on the Italian general population. Brain, Behav Immun. 2020;87(2020):75-79.

doi: 10.1016/j.bbi.2020.04.048.

4. Yáñez JA, Jahanshahi AA, Alvarez-Risco A, Li J,Zhang SX. Anxiety, Distress, and Turnover Intention of Healthcare Workers in Peru by Their Distance to the Epicenter during the COVID-19 Crisis. Am J Trop Med Hyg. 2020;00(0):1-7. doi: 10.4269/ajtmh.20-0800.

5. Zhang SX, Sun S, Jahanshahi AA, Alvarez-Risco A, Ibarra VG, Li J, et al. Developing and testing a measure of COVID-19 organizational support of healthcare workers - results from Peru, Ecuador, and Bolivia. Psychiatry Res. 2020;291(2020):113174. doi: 10.1016/j.psychres.2020.113174.

6. Salman M, Asif N, Mustafa ZU, Khan TM, Shehzadi N, Hussain K, et al. Psychological impact of COVID-19 on Pakistani university students and how they are coping. medRxiv. 2020; doi: 10.1101/2020.05.21.20108647.

7. Slovic P. Perception of risk. Science. 1987;236(4799):280-285. doi: 10.1126/science.3563507.

8. Li S, Rao LL, Bai XW, Zheng R, Ren XP, Li JZ, et al. Progression of the "Psychological typhoon eye" and variations since the Wenchuan earthquake. PLoS ONE. 2010;5(3):e9727. doi:

10.1371/journal.pone.0009727.

9. Xie XF, Stone E, Zheng R, Zhang RG. The 'Typhoon Eye Effect': determinants of distress during the SARS epidemic. J Risk Res. 2011;14(9):1091-1107. doi: 10.1080/13669877.2011.571790.

10. Hoven CW, Duarte CS, Lucas CP, Wu P, Mandell DJ, Goodwin RD, et al. Psychopathology among New York City public school children 6 months after September 11. Arch Gen Psychiatry. 2005;62(5):545552. doi: 10.1001/archpsyc.62.5.545.

11. Zheng R, Rao LL, Zheng XL, Cai C, Wei ZH, Xuan YH, et al. The more involved in lead-zinc mining risk the less frightened: A psychological typhoon eye perspective. J Environ Psychol. 
2015;44(2015):126e134. doi: 10.1016/j.jenvp.2015.10.002.

12. Zhang Y, Cao X, Wang P, Wang G, Lei G, Shou Z, et al. Emotional "inflection point" in public health emergencies with the 2019 new coronavirus pneumonia (NCP) in China. J Affect Disord. 2020;276(2020):797-803. doi: 10.1016/j.jad.2020.07.097.

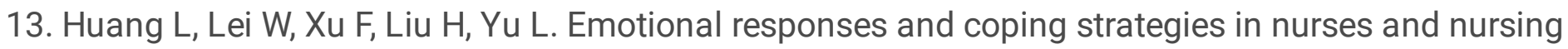
students during Covid-19 outbreak: A comparative study. PLoS ONE. 2020;15(8):e0237303. doi: $10.1371 /$ journal.pone.0237303.

14. Tang PM, Zhang SX, Li CH, Wei F. Geographical identification of the vulnerable groups during COVID19 crisis: The typhoon eye effect and its boundary conditions. Psychiat Clin Neuros. 2020;doi:10.1111/pcn.13114.

15. Zhang L, Ma M, Li D, Xin Z. The psychological typhoon eye effect during the COVID-19 outbreak in China: The role of coping efficacy and perceived threat. Global Health. 2020;16:105. doi.org/10.1186/s12992-020-00626-8.

16. Zhang SX, Wang Y, Jahanshahi AA, Li J, Schmitt VGH. Mental distress of adults in Brazil during the COVID-19 crisis. medRxiv. 2020;doi: 10.1101/2020.04.18.20070896.

17. Official updates coronavirus; COVID-19 in Pakistan. http://covid.gov.pk/stats/pakistan. (Accessed on June 02, 2020).

18. World population review; Karachi population 2020 (Demographics, Maps, Graphs). https://worldpopulationreview.com/world-cities/karachi-population. (Accessed on June 02, 2020).

19. Kessler RC, Andrews G, Colpe LJ, Hiripi E, Mroczek DK, Normand SLT, et al.. Short screening scales to monitor population prevalences and trends in non-specific psychological distress. Psychol Med. 2002;32(6):959-976. doi: 10.1017/s0033291702006074.

20. Chen J, Zhang SX, Wang Y, Jahanshahi AA, Dinanie MM, Madavanif AN, et al. The curvilinear relationship between the age of adults and their mental health in Iran after its peak of COVID-19 cases. medRxiv. 2020;doi: 10.1101/2020.06.11.20128132.

21. Kroenke K, Spitzer RL, Williams JBW, Löwe B. An ultra-brief screening scale for anxiety and depression: The PHQ-4. Psychosomatics. 2009;50(6):613-21. doi: 10.1176/appi.psy.50.6.613.

22. Chen X, Zhang SX, Jahanshahi AA, Alvarez-Risco A, Dai H, Li J, et al. Belief in a COVID-19 Conspiracy Theory as a Predictor of Mental Health and Well-Being of Health Care Workers in Ecuador: CrossSectional Survey Study. JMIR Public Health Surveill. 2020;6(3):e20737. doi: 10.2196/20737.

23. Ware JJr, Kosinski M, Keller SD. A 12-Item short-form health survey: construction of scales and preliminary tests of reliability and validity. Med Care. 1996;34(3):220-233. doi: 10.1097/00005650199603000-00003.

24. Zhang SX, Wang Y, Rauch A, Wei F. Unprecedented disruption of lives and work: Health, distress and life satisfaction of working adults in China one month into the COVID-19 outbreak. Psychiatry Res. 2020;2020(288):112958. doi: 10.1016/j.psychres.2020.112958.25. Song K, Xu R, Stratton TD, Kavcic V, Luo D, Hou F, et al. Sex differences and psychological stress: Responses to the COVID-19 epidemic in China. Res Square. 2020;doi: 10.1101/2020.04.29.20084061. 
25. Dai H, Zhang SX, Looi KH, Su R, Li J. Perception of health conditions and test availability as predictors of adults' mental health during the COVID-19 pandemic: A survey study of adults in Malaysia. Int J Env Res Pub He. 2020;17:5498. doi: 10.3390/ijerph17155498.

26. Ahmad A, Rahman I, Agarwal M. Early psychosocial predictors of mental health among Indians during coronavirus disease 2019 outbreak. J Health Sci. 2020;X(X):1-10. doi: 10.17532/jhsci.2020.950.

27. Zhang J, Lu H, Zeng H, Zhang S, Du Q, Jiang T, et al. The differential psychological distress of populations affected by the COVID-19 pandemic. Brain Behav Immun. 2020;87(2020):49-50. doi: 10.1016/j.bbi.2020.04.031.

28. Twenge J, Joiner TE. Mental distress among U.S. adults during the COVID-19 pandemic. PsyArXiv. 2020;doi:10.31234/osf.io/wc8ud.

29. González-Sanguino C, Ausín B, Castellanos MA, Saiz J, López-Gómez A, Ugidos C, et al. Mental health consequences during the initial stage of the 2020 Coronavirus pandemic (COVID-19) in Spain. Brain Behav Immun. 2020;87(2020):172-176. doi: 10.1016/j.bbi.2020.05.040.

30. Zhang SX, Huang H, Wei F. Geographical distance to the epicenter of Covid-19 predicts the burnout of the working population: Ripple effect or typhoon eye effect? Psychiatry Res. 2020;288(2020):112998. doi: 10.1016/j.psychres.2020.112998.

31. Knapp M, Wong G. Economics and mental health: The current scenario. World Psychiatry. 2020;19:314.doi: 10.1002/wps.20692.

32. Qureshi S, Riaz H, Awan MM, Khushnood K, Hussain R. Association of depression, physical activity levels and general psychological health among physical therapy students of Rawalpindi and Islamabad. J. Shifa Tameer-e-Millat Uni. 2019;2(1):26-30. doi:10.32593/jstmu/Vol2.Iss1.27.

33. 34. Nowak PF, Bozek A, Blukacz M. Physical activity, sedentary behavior and quality of life among university students. Biomed Res. Int. 2019;2019:9791281. doi: 10.1155/2019/9791281.

34. Peyman N, Olyani S. Iranian older adult's mental wellbeing during the COVID-19 epidemic. Asian J Psychiatr. 2020;54(2020):102331. doi: 10.1016/j.ajp.2020.102331.

35. Qiu J, Shen B, Zhao M, Wang Z, Xie B, Xu Y. A nationwide survey of psychological distress among Chinese people in the COVID-19 epidemic: implications and policy recommendations. Gen. Psychiatr. 2020;33:e100213. doi: 10.1136/ gpsych-2020-100213.

36. Zhang, SX, Wang Y, Jahanshahi AA, Schmitt VGH. First study on mental distress in Brazil during the COVID-19 crisis. medRxiv. 2020;doi: 10.1101/2020.04.18.20070896.

37. Taqui AM, Itrat A, Qidwai W, Qadri Z. Depression in the elderly: Does family system play a role? A cross-sectional study. BMC Psychiatry. 2007;7:57. doi: 10.1186/1471-244X-7-57.

38. Jeronimus BF, Snippe E, Emerencia AC, de Jonge P, Bos EH. Acute stress responses after indirect exposure to the MH17 airplane crash. Br. J. Psychol. 2019;110(4):790-813. doi: 10.1111/bjop.12358.

39. Wang H, Xia Q, Xiong Z, Li Z, Xiang W, Yuan Y, et al. The psychological distress and coping styles in the early stages of the 2019 coronavirus disease (COVID-19) epidemic in the general mainland 
Chinese population: A web-based survey. PLoS ONE. 2020;15(4):e0233410. doi: 10.1371/journal.pone.0233410.

40. Guo Q, Zheng Y, Shi J, Wang J, Li G, Li C, et al. Immediate psychological distress in quarantined patients with COVID-19 and its association with peripheral inflammation: A mixed-method study. Brain, Behav. Immun. 2020;88(2020):17-27. doi: 10.1016/j.bbi.2020.05.038.

41. Gao J, Zheng P, Jia Y, Chen H, Mao Y, Chen S, et al. Mental health problems and social media exposure during COVID-19 outbreak. PLoS ONE. 2020;15(4):e0231924. doi: 10.1371/journal.pone.0231924.

42. Ni MY, Yang L, Leung CMC, Li N, Yao X, Wang Y, et al. Mental health, risk factors, and social media use during the COVID-19 epidemic and cordon sanitaire among the community and health professionals in Wuhan, China: Cross-sectional survey. JMIR Ment Health. 2020;7(5):e19009. doi: 10.2196/19009.

43. Meng H, Xu Y, Dai J, Zhang Y, Liu B, Yang H. Analyze the psychological impact of COVID-19 among the elderly population in China and make corresponding suggestions. Psychiatry. Res. 2020;289(6):112983. doi: 10.1016/j.psychres.2020.112983.

\section{Tables}

Due to technical limitations, table 1-2 is only available as a download in the Supplemental Files section.

\section{Figures}




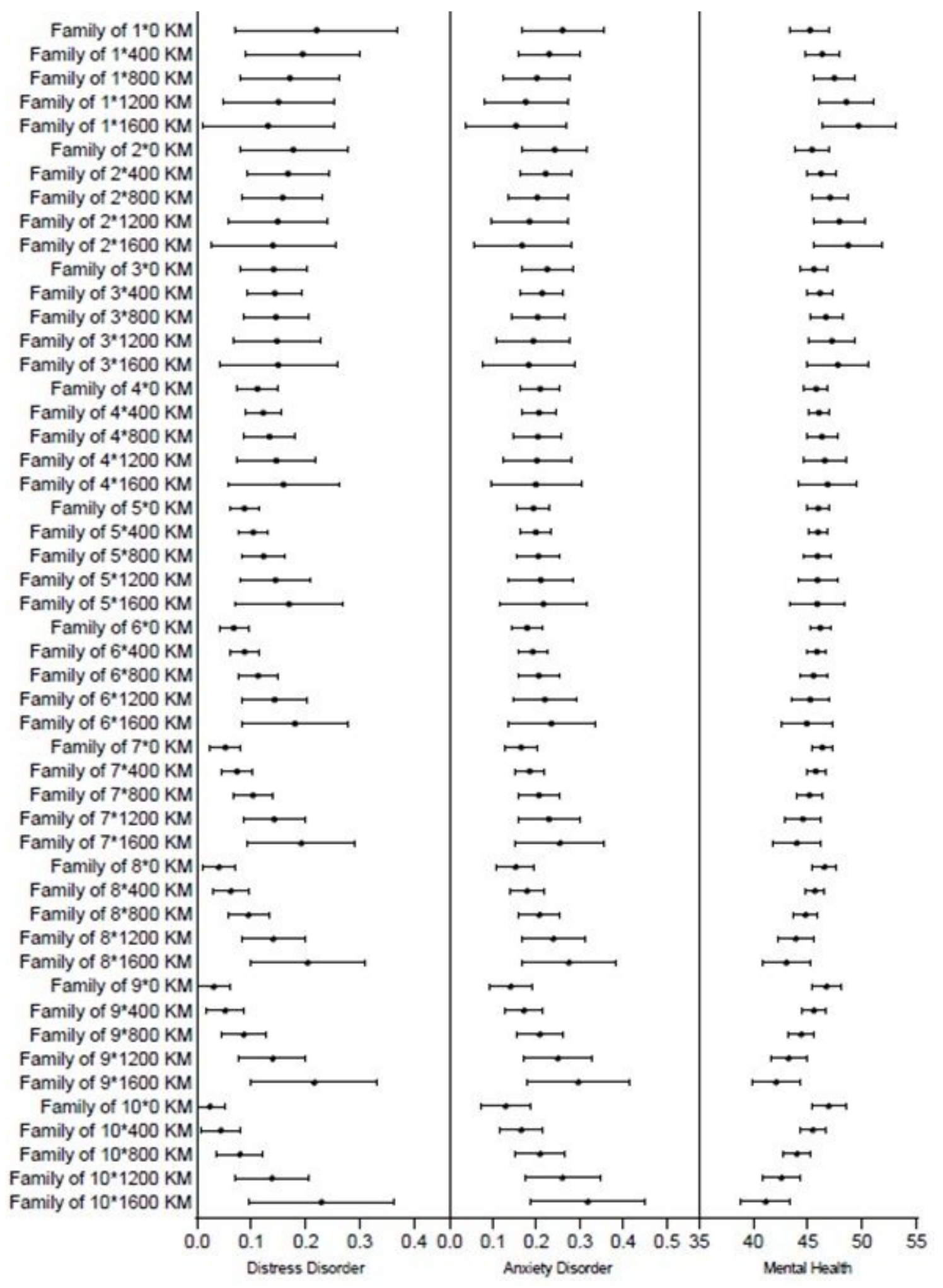

Figure 1

Predicted value and $95 \%$ confidence intervals of distress disorder, anxiety order and overall mental health score by family size and distance to the epicenter 
This is a list of supplementary files associated with this preprint. Click to download.

- Tables.docx 